\title{
Extrascleral Tumor Extension Associated with Localized Scleral Melt following Plaque Brachytherapy for Uveal Melanoma: Clinical and Histologic Findings
}

\author{
Chau M. Pham ${ }^{a}$ Steven M. Couch ${ }^{a}$ George J. Harocopos ${ }^{a, b}$ \\ Departments of a Ophthalmology and Visual Sciences and ${ }^{b}$ Pathology and Immunology, Washington University \\ School of Medicine, St. Louis, MO, USA
}

\section{Keywords}

Choroidal melanoma - Uveal melanoma ${ }^{125}$ I brachytherapy . Plaque brachytherapy · Histopathology

\begin{abstract}
Background/Aims: Our study aims to better characterize the clinical and histopathologic features of eyes with extrascleral uveal melanoma associated with scleral melt following brachytherapy. Methods: A retrospective review was performed on patients who had undergone ${ }^{125}$ (iodine-125) brachytherapy for uveal melanoma at our institution between 1992 and 2015. Patients with postradiation scleral necrosis who required enucleation were identified, and an analysis including a review of histopathology results was performed on those cases. Results: A total of 301 patients underwent plaque brachytherapy for uveal melanoma, of whom 31 required eventual enucleation. The histologic analysis showed extraocular extension through full-thickness scleral discontinuities in 6 cases. All but 1 (5 of 6 ) of these eyes exhibited either mitotic figures or Ki-67 positivity. Mitotic figures were noted in 4 specimens, including 3 eyes exhibiting mitoses within or adjacent to the extrascleral portion of the tumor. Two eyes exhibiting mitoses, as well as the case with Ki-67 positivity, also had clinical evidence of tumor
\end{abstract}

regrowth. Conclusion: We found evidence of mitotic activity at the area of scleral discontinuity in some eyes with and in some without clinical evidence of tumor regrowth. Protruding pigmented material in areas of scleral necrosis after plaque brachytherapy may represent actively proliferating tumors even without internal evidence of tumor regrowth.

(c) 2017 S. Karger AG, Basel

\section{Introduction}

Scleral necrosis is a known complication of plaque radiotherapy for uveal melanoma, with a reported incidence of $0-33 \%$ [1-5]. Proposed mechanisms include a direct necrotizing effect of radiation on the sclera, a secondary effect due to local ischemic inflammation from muscle disinsertion, inflammation related to tumor necrosis, regression of the tumor with undiagnosed scleral invasion, and an occult systemic autoimmune phenomenon $[2,4,6]$. Factors found to be related to postradiation scleral necrosis include the initial tumor thickness, radia-

This study was previously presented in poster format at the Association for Research in Vision and Ophthalmology (ARVO) 2016 Annual Meeting.

\section{KARGER}

(c) 2017 S. Karger AG, Basel

E-Mail karger@karger.com

www.karger.com/oop
Chau M. Pham, MD

Washington University School of Medicine

660 South Euclid Avenue, Box 8096

St. Louis, MO 63110 (USA)

E-Mail phamc@vision.wustl.edu 


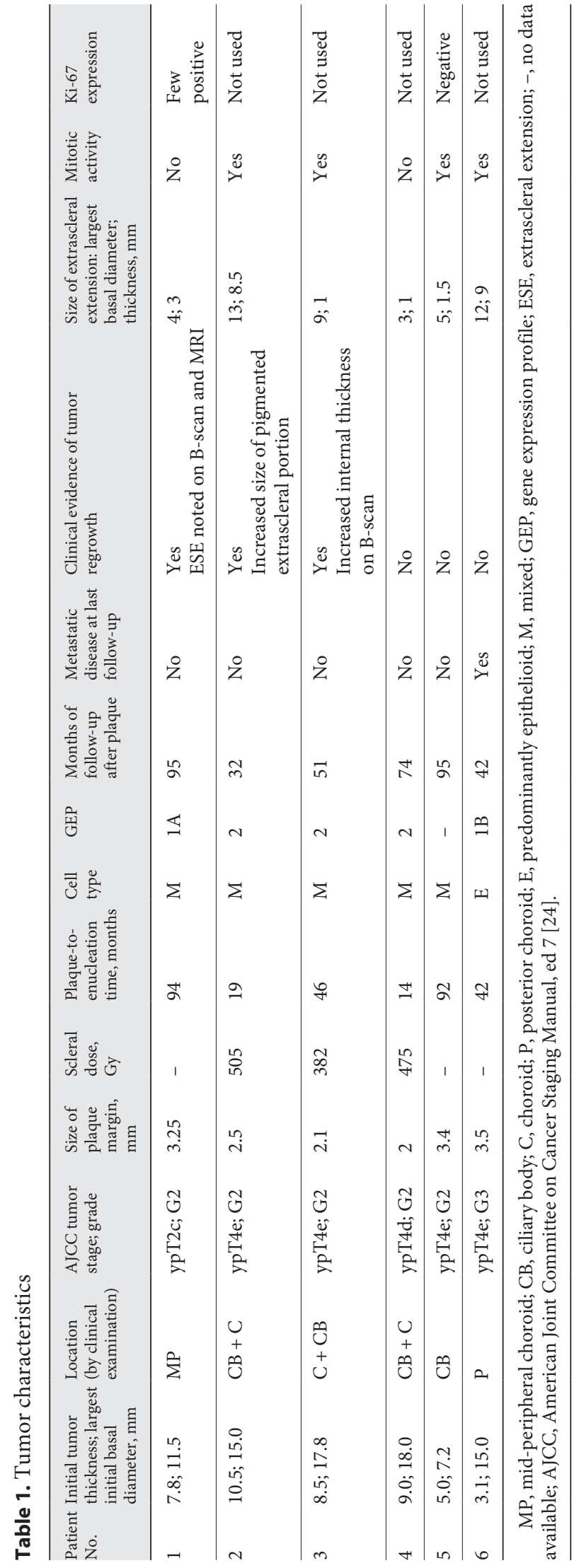

tion dose to the tumor base, ciliary body/anterior location of the tumor, and intraocular pressure $[2,4,5]$.

The diagnosis of scleral thinning and necrosis is made clinically, and the diagnostic dilemma lies in differentiating herniation of an inactive tumor through the necrotic sclera from active tumor regrowth. Some authors have observed that tumor recurrence is associated with a concurrent increase in basal diameter or thickness of the tumor and a tumor shadow on transillumination, and they do concede that there can be scleral thinning combined with tumor recurrence [5]. Currently, treatment options for scleral thinning and necrosis include observation and scleral or corneal patch grafts, with the aim of preventing perforation of the globe (reported in 4-9\% of cases of post-plaque-brachytherapy scleral thinning) $[4,5]$.

Our study aims to better characterize the clinical and histopathologic features of patients with presence of an extrascleral tumor associated with scleral melt following brachytherapy.

\section{Methods}

After approval by our institution's review board, a retrospective review was performed on the clinical records of patients who had undergone ${ }^{125}$ I plaque brachytherapy for uveal melanoma between 1992 and 2015, in order to identify a subset of patients with scleral necrosis ultimately necessitating enucleation. The radiation dose prescription was $85 \mathrm{~Gy}$ to the tumor apex for tumors $\geq 5 \mathrm{~mm}$, and $85 \mathrm{~Gy}$ to the center for tumors $\leq 5 \mathrm{~mm}$, and the plaques were sized to allow a 2- to 3-mm margin on all sides of the tumor. The histopathology including immunohistochemical staining that had been performed on the enucleated globes was reviewed. For each globe, there were 25-60 H\&E (hematoxylin-eosin)-stained sections (each 3-5 $\mu \mathrm{m}$ thick) derived from 2-3 paraffin-embedded tissue blocks (the pupil-optic nerve section and one or both calottes). The presence of morphologically intact melanoma cells was confirmed with Mart-1/tyrosinase-red immunostaining. Ki67 immunostaining had been carried out on 2 of the 6 samples. Extrascleral extension was defined as the presence of morphologically intact tumor cells outside of the sclera. Gene expression profiling (GEP) data were also reviewed.

\section{Results}

The clinical, histopathologic, immunohistochemical, and molecular diagnostic (GEP) data are reported in Table 1 . There were 301 cases of uveal melanoma treated with ${ }^{125}$ I plaque brachytherapy identified in our institutional record review from 1992 to 2015. The rate of postbrachytherapy scleral necrosis ultimately requiring enucleation was $2 \%(6 / 301)$. 

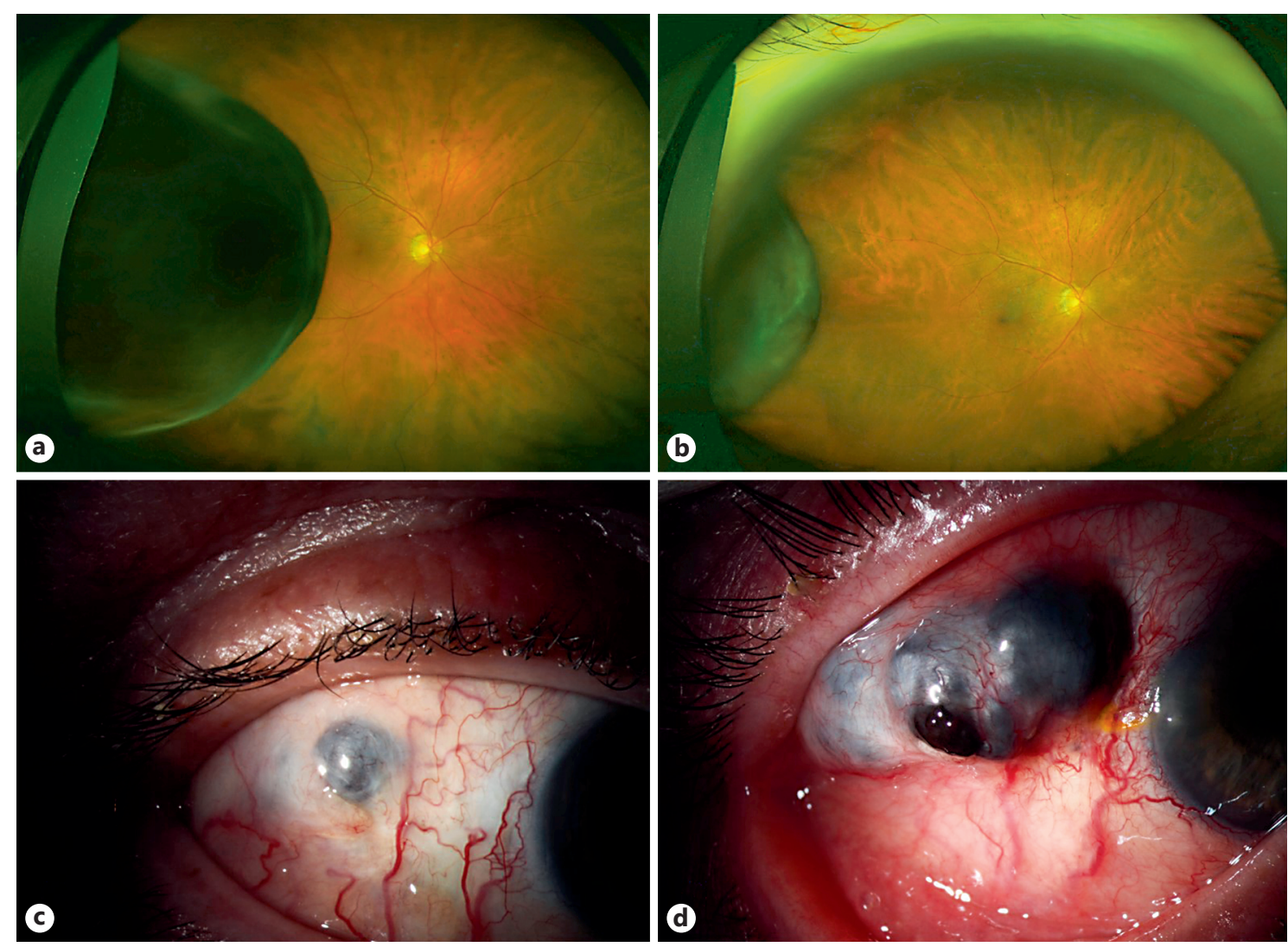

Fig. 1. Fundus (a, b) and external (c, d) photographs of case 2. Before (a) and 11 months after plaque brachytherapy (b). Scleral necrosis with an episcleral nodule 7 months (c) and 19 months (d) after plaque brachytherapy.

For these 6 cases, the mean patient age at plaque placement was 66 years (range 54-83), and the average followup from plaque placement was 65 months (range 32-95), with metastatic disease in 1 patient. No patients had an ocular history of scleritis or diseases predisposing to scleral melt. The average initial tumor thickness was 7.1 $\mathrm{mm}$ (range 3.1-10.5). By clinical evaluation, 4 tumors were anterior (exclusively, predominantly, or partially involving the ciliary body), 1 tumor was mid-peripheral, and 1 was posterior (including the peripapillary component). Three eyes had clinical evidence of tumor regrowth. Of these, 1 exhibited extraocular extension by B-scan as well as MRI without change in the intraocular portion, 1 had an increased intraocular tumor thickness as measured by B-scan without evidence of external change (although this patient had had a scleral patch graft placed), and 1 exhibited an increased size of the external pigmented lesion (Fig. 1). GEP showed class $1 \mathrm{~A}$ in 1 case, class 1B in 1 case, and class 2 in 3 cases; it had not been performed in 1 case. Histologic analysis showed extraocular exten- sion of morphologically intact tumor cells through fullthickness scleral discontinuities in all (6/6) cases. Scleral discontinuities occurred in the region covered by the plaque in all (6/6) cases, with 1 case (case No. 3) exhibiting an additional discontinuity at the anterior edge of the plaque site near the corneoscleral limbus. In 4 of the 6 cases, the extrascleral portion of the tumor measured at least $5 \mathrm{~mm}$ in maximal dimension.

The specimens had varying proportions of morphologically intact tumor that stained positive with Mart-1/ tyrosinase-red. The cell type was predominantly epithelioid in 1 specimen, and mixed spindle/epithelioid in 5 specimens. Mitotic figures (though sparse) were noted in 4 specimens, including 3 eyes exhibiting mitoses within or adjacent to the extrascleral portion of the tumor (Fig. 2). Of the specimens exhibiting mitoses, 2 were in patients with, and 2 in patients without, clinical evidence of tumor regrowth. Ki-67 staining was available for 2 of the 6 samples. Of these, 1 was positive for proliferative activity (no mitotic figures had been detected in this case), 

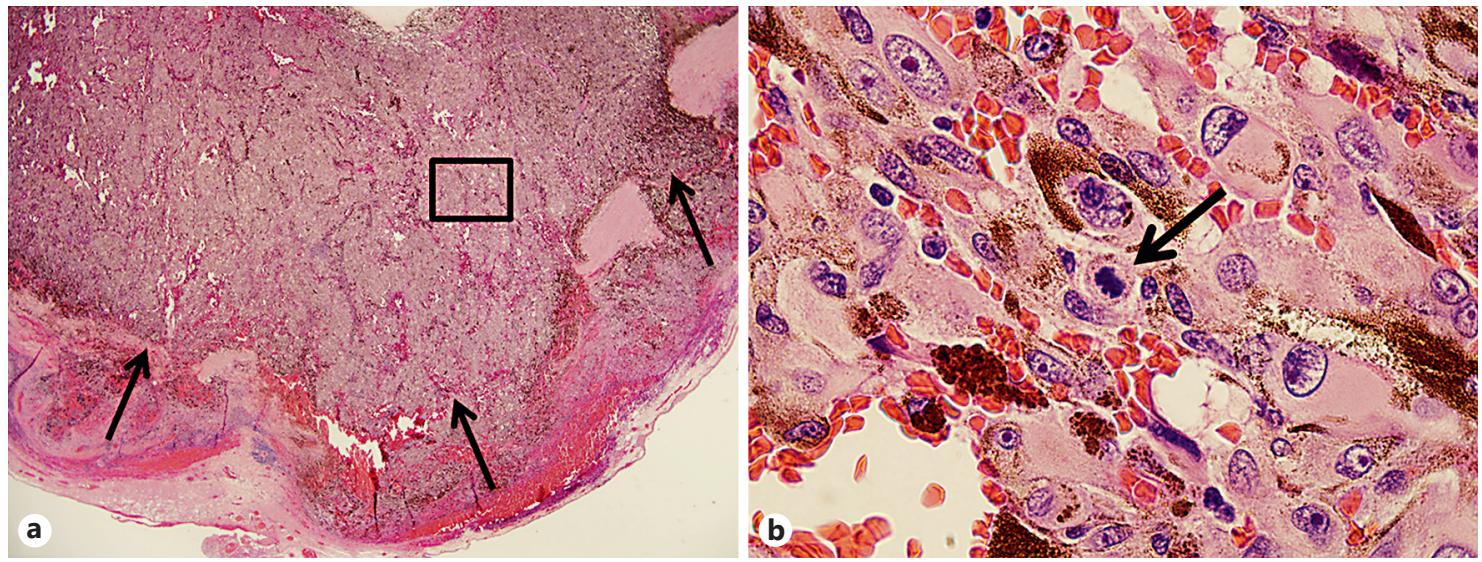

Fig. 2. H\&E sections of the enucleated globe from case 2. a Low-power view showing extrascleral extension through 3 scleral discontinuities (arrows). b High-power view of the boxed area from a showing a mitotic figure (arrow) within the neck of the tumor in the region of the scleral melt.

and in this case there was also clinical evidence of tumor regrowth. In the other case, Ki-67 staining was negative despite the identification of occasional mitotic figures.

\section{Discussion}

Scleral necrosis as a complication of irradiation of ocular tissues has been described as far back as the 1950s [7, 8]. Necrosis after plaque brachytherapy of any kind for malignant intraocular tumors has been reported in $0-33 \%$ of patients [1-5]. For uveal melanomas treated with ${ }^{125} \mathrm{I}$ brachytherapy, necrosis was seen in $11 \%$ of patients with predominantly ciliary body involvement [2], while Shields et al. [3] reported necrosis in $7 \%$ at 5 years and $9 \%$ at 10 years in patients with large posterior uveal melanomas. In our series, the rate of post-plaque-brachytherapy scleral necrosis requiring enucleation was found to be $2 \%$ $(6 / 301)$, with the majority of these tumors (4/6) involving the ciliary body. Because our clinical record search was not designed to hit all cases of post-plaque-brachytherapy scleral necrosis, but only those cases ultimately necessitating enucleation, the rate of all cases of post-brachytherapy scleral necrosis in our patient population is likely higher than $2 \%$, similar to other published data. A casecontrol study by Kaliki et al. [4] found that cases with scleral necrosis were more likely to have larger initial basal tumor diameters; however, on multivariate analysis, factors predictive of scleral necrosis included an initial tumor thickness $\geq 6-7 \mathrm{~mm}$, a peripheral tumor location (ciliary body), and a radiation dose $\geq 400$ Gy to the sclera
$[2,5]$. These studies did not comment on whether there was a relationship between scleral necrosis and tumor regrowth or treatment failure. In our cohort, 4 of the 6 cases had an initial tumor thickness $\geq 6 \mathrm{~mm}, 4$ of the 6 involved the ciliary body, and 2 of 3 cases in which scleral dosing information was available had a radiation dose $\geq 400$ Gy. The highest scleral dose (505 Gy) was associated with the largest initial tumor thickness $(10.5 \mathrm{~mm})$ and the largest basal dimension of extraocular extension $(13 \mathrm{~mm})$.

Whether or not protrusion of pigmented material represents extrascleral extension of a growing tumor or benign herniation of an inactive tumor likely carries prognostic weight. Both extrascleral tumor extension and post-irradiation tumor recurrence are associated with an increased risk of metastasis and death [9-11]. Furthermore, the presence of extrascleral extension is associated with an increased risk of local orbital recurrence following enucleation ( $\mathrm{HR}=3.2$; 95\% CI: $1.5-6.7 ; p=0.003$ ) [11]. All specimens in our study exhibited extraocular extension of morphologically intact tumor cells through the necrotic sclera, and 5 of the 6 cases exhibited some evidence of tumor cell proliferation, suggesting that the extrascleral extension in these 5 cases signified some degree of tumor regrowth, therefore possibly conferring an increased risk of orbital recurrence, metastasis, and death. However, it is presently unknown whether extrascleral extension via post-brachytherapy regrowth of a tumor through the necrotic sclera carries the same prognostic significance as extrascleral extension of an untreated tumor via the traditional route of emissary canal invasion. 
Furthermore, it is possible that proliferative activity in the absence of clinical evidence of tumor regrowth (of which there were 2 cases in our series) may not have the same prognostic significance as proliferative activity in the context of a clinically expanding tumor (of which there were 3 cases), as it may be presumed in the former scenario that the tumor is proliferating at an extremely slow rate. Additionally, the prognostic value of the size of postplaque-brachytherapy extraocular extension for metastasis cannot be determined from such a small cohort of cases. Of the 2 cases with the largest volume of extrascleral extension, one was the only case with metastatic disease at the time of data acquisition (extraocular extension measured: $12 \mathrm{~mm}$ basal $\times 9 \mathrm{~mm}$ thickness), while in the other case no clinically detectable metastatic disease had yet developed (extraocular extension measured: $13 \mathrm{~mm}$ basal $\times 8.5 \mathrm{~mm}$ thickness).

Currently, it is posited that the overall natural history of post-plaque-brachytherapy scleral necrosis is a benign one, and that in most cases protruding pigmented material represents herniation of an inactive tumor rather than tumor regrowth. One case series found necrosis and the volume of extrascleral pigmented lesions to be stable in $75 \%$, whereas a case-control study of 73 cases found necrosis to be stable in $48 \%$, while it was increasing in size or severity in $48 \%[4,5]$. These studies focused primarily on the natural history of scleral necrosis rather than the histopathology. Histopathology results were not reported in the study by Kaliki et al. [5] (no biopsies were reported, and no histology was reported for the 4 eyes requiring enucleation - 1 for endophthalmitis and 3 for neovascular glaucoma and/or blind painful eye). An analysis was carried out for 5 of 23 eyes in the case series by Radin et al. [4], wherein the authors reported that they did not find evidence of tumor cells in any of the 3 biopsies taken of the suspicious episcleral pigmented lesions (only macrophages were seen), and they did not comment on the presence/absence of tumor cell proliferative activity on histopathology of the 2 enucleated eyes.

In cases of scleral melt after plaque brachytherapy, it is hypothesized that the radiation effect would render residual tumor cells unviable. In studies in which histopathologic analyses were performed on post-enucleation specimens without scleral melt, less mitotic activity was found in post-plaque-brachytherapy eyes compared to those primarily enucleated, even though the authors note that whether this represents a direct cytotoxicity/radiation effect or slower-growing tumors at baseline is difficult to determine [12-14]. Histologic examinations and in vitro studies of melanoma cell growth after pre-enu-

Extension of Uveal Melanoma via Scleral

Melt after Plaque Brachytherapy cleation external beam radiation have found decreased mitotic and Ki-67 activity, and decreased cell adhesion, growth, and viability in cell culture, attributable to the radiation effect [15-17]. Meanwhile, another study found no mitotic figures and furthermore found evidence of "reproductive cell death" (defined as increased doubling time) in 3 fresh post-irradiation samples submitted for cell culture [18] (though it is worth noting that none of the samples submitted for cell culture were from eyes enucleated for suspicion of tumor regrowth). However, some authors have found evidence of mitotic activity after plaque radiotherapy, particularly in eyes with clinical evidence of tumor regrowth [19]. In the current study, proliferative activity was noted in 5 of the 6 specimens (mitotic figures in 4 , and Ki-67 positivity in 1), including 3 eyes exhibiting mitoses within or adjacent to the extrascleral portion of the tumor. Furthermore, 2 of the specimens exhibiting mitosis were in eyes without clinical evidence of tumor regrowth at the time of enucleation. These findings demonstrate that even in the absence of other clinical measures for regrowth, protrusion of pigmented material may in fact represent tumor growth, even though it is likely to be quite slow in such cases.

In addition to the presence of mitotic figures, Ki-67 immunostaining is used as a marker of cell proliferation [20]. In our series, Ki-67 staining had been performed on 2 of the 6 samples. Of these, 1 demonstrated positive evidence of cell proliferation that had not been detected via examination for mitotic figures, correlating with clinical evidence of tumor regrowth in this case. The GEP in this case was class $1 \mathrm{~A}$. In the other case, Ki-67 staining was negative despite the identification of sparse mitotic activity on $\mathrm{H} \& \mathrm{E}$ staining, thereby indicating that the rate of tumor cell proliferation was very low (presumably $<1$ cell, on average, per histologic section), correlating with the absence of clinical evidence of tumor regrowth in that case. GEP data were not available for that specimen. It was not entirely necessary to retrospectively perform $\mathrm{Ki}$ 67 staining in the remaining cases, as the presence of mitotic activity had already been established via mitotic figures on routine histology in 3 of the remaining 4 cases. Also of note, heavy scattering of melanin pigment, some of which may be engulfed by melanophages, was often found in such post-brachytherapy cases, and it was therefore anticipated that the brown-colored chromogen of the Ki-67 stain used in our pathology laboratory, despite being combined with Mart-1-red to identify melanocytes, would be quite challenging to interpret. The future acquisition of a combined Ki-67-blue/Mart-1-red immuno- 
stain in our laboratory would help facilitate assessment of the cell proliferation index in such cases.

Not only has class $1 \mathrm{~B}$ and 2 GEP been associated with a higher tumor-related mortality rate, as has the presence of epithelioid morphology on histology, but class 2 GEP is also associated with higher Ki-67 expression and tumor cell proliferation $[21,22]$. Among the 5 cases in our series in which GEP information was available, 4 specimens exhibited either class $1 \mathrm{~B}$ or class 2 , correlating for the most part with the high prevalence of epithelioid cells in our cases (5 with mixed cell morphology, 1 predominantly epithelioid). Only 1 case developed metastatic disease by the time of data acquisition, and the specimens in this case exhibited class 1B GEP and predominantly epithelioid cell morphology. Given the relationship between class 2 GEP and proliferative index, it may be posited that pigmented tissue in the region of scleral necrosis may be more likely to represent an active tumor if the tumor has an epithelioid cell morphology and expresses class 2 (or class 1B) GEP. However, the pre-radiation proliferation rate may not correlate with the likelihood of post-radiation proliferation: Chappell et al. [23] found that postradiation recurrence was not predicted by GEP, and the small size of the current series precludes elucidation of the true relationship between GEP and the likelihood of post-brachytherapy cell proliferation.

In summary, in our series of enucleated eyes with scleral necrosis after brachytherapy for uveal melanoma, we found evidence of tumor cell proliferative activity in some eyes with, and in some eyes without, clinical evidence of tumor regrowth, and in these cases, the proliferative activity was generally identified in the vicinity of scleral discontinuity. Protruding pigmented lesions in ar- eas of scleral necrosis after plaque radiotherapy may represent herniation of an inactive tumor in the majority of cases, and a limitation of our study is that it included only cases culminating in enucleation, with corresponding histologic confirmation, and therefore our results cannot necessarily be extrapolated to all cases of clinically observed post-plaque-brachytherapy scleral melt. Our study does, however, establish that at least some cases of extrascleral pigmented lesioning in the vicinity of post-plaquebrachytherapy scleral melt may represent actively proliferating tumors even without internal evidence of tumor regrowth. Considerations regarding the management of scleral necrosis following plaque brachytherapy for uveal melanoma should include not only clinical observations of tumor growth, but perhaps also the GEP status, along with tumor cell morphology.

\section{Acknowledgements}

This study was supported by an unrestricted grant from Research to Prevent Blindness.

\section{Statement of Ethics}

This retrospective chart review study was undertaken with IRB approval (\#201312030) from Washington University in Saint Louis, MO, USA.

\section{Disclosure Statement}

The authors have no conflicts of interest related to this topic.

\section{References}

1 Conway RM, Poothullil AM, Daftari IK, Weinberg V, Chung JE, O’Brien JM: Estimates of ocular and visual retention following treatment of extra-large uveal melanomas by proton beam radiotherapy. Arch Ophthalmol 2006; 124:838-843.

2 Gündüz K, Shields CL, Shields JA, Cater J, Freire JE, Brady LW: Plaque radiotherapy of uveal melanoma with predominant ciliary body involvement. Arch Ophthalmol 1999; 117:170-177.

3 Shields CL, Naseripour M, Cater J, Shields JA, Demirci H, Youseff A, Freire J: Plaque radiotherapy for large posterior uveal melanomas ( $>$ or $=8-\mathrm{mm}$ thick) in 354 consecutive patients. Ophthalmology 2002;109:1838-1849.
4 Radin PP, Lumbroso-Le Rouic L, Levy-Gabriel C, Dendale R, Sastre X, Desjardins L: Scleral necrosis after radiation therapy for uveal melanomas: report of 23 cases. Graefes Arch Clin Exp Ophthalmol 2008;246:1731-1736.

5 Kaliki S, Shields CL, Rojanaporn D, Badal J, Devisetty L, Emrich J, Komarnicky L, Shields JA: Scleral necrosis after plaque radiotherapy of uveal melanoma: a case-control study. Ophthalmology 2013;120:1004-1011.

6 Corréa ZM, Augsburger JJ, Freire J, Eagle RC Jr: Early-onset scleral necrosis after iodine I 125 plaque radiotherapy for ciliochoroidal melanoma. Arch Ophthalmol 1999;117:259261.
7 Jones IS, Reese AB: Focal scleral necrosis; a late sequel of irradiation. AMA Arch Ophthalmol 1953;49:633-636.

8 Macfaul PA, Bedford MA: Ocular complications after therapeutic irradiation. Br J Ophthalmol 1970;54:237-247.

9 Harbour JW, Char DH, Kroll S, Quivey JM, Castro J: Metastatic risk for distinct patterns of postirradiation local recurrence of posterior uveal melanoma. Ophthalmology 1997; 104:1785-1792; discussion 1792-1793.

10 Shields CL, Kaliki S, Furuta M, Fulco E, Alarcon C, Shields JA: American Joint Committee on Cancer classification of posterior uveal melanoma (tumor size category) predicts prognosis in 7,731 patients. Ophthalmology 2013;120:2066-2071. 
11 Gallie BL, Simpson ER, Saakyan S, Amiryan A, Valskiy V, Finger PT, Chin KJ, Semenova E, Seregard S, Fili M, Wilson M, Haik B, Caminal JM, Català J, Gutierrez C, Pelayes DE, Folgar AM, Jager MJ, Dogrusöz M, Luyten GP, Singh A, Schachat AP, Suzuki S, Aihara $Y$ : Local recurrence significantly increases the risk of metastatic uveal melanoma. Ophthalmology 2016;123:86-91.

12 Albert DM, Diener-West M, Robinson NL, Grossniklaus HE, Green WR, Vine AK, et al: Histopathologic characteristics of uveal melanomas in eyes enucleated from the Collaborative Ocular Melanoma Study. COMS report No. 6. Am J Ophthalmol 1998;125:745-766.

13 Crawford JB, Char DH: Histopathology of uveal melanomas treated with charged particle radiation. Ophthalmology 1987;94:639643.

14 Avery RB, Diener-West M, Reynolds SM, Grossniklaus HE, Green WR, Albert DM: Histopathologic characteristics of choroidal melanoma in eyes enucleated after iodine 125 brachytherapy in the collaborative ocular melanoma study. Arch Ophthalmol 2008;126: 207-212.
15 Mooy CM, de Jong PT, Van der Kwast TH, Mulder PG, Jager MJ, Ruiter DJ: Ki-67 immunostaining in uveal melanoma. The effect of pre-enucleation radiotherapy. Ophthalmology 1990;97:1275-1280.

16 Kenneally CZ, Farber MG, Smith ME, Devineni R: In vitro melanoma cell growth after preenucleation radiation therapy. Arch Ophthalmol 1988;106:223-224.

17 Augsburger JJ, Eagle RC Jr, Chiu M, Shields JA: The effect of pre-enucleation radiotherapy on mitotic activity of choroidal and ciliary body melanomas. Ophthalmology 1987;94: 1627-1630.

18 Brantley MA Jr, Worley L, Harbour JW: Altered expression of $\mathrm{Rb}$ and $\mathrm{p} 53$ in uveal melanomas following plaque radiotherapy. Am J Ophthalmol 2002;133:242-248.

19 Shields CL, Shields JA, Karlsson U, Menduke $\mathrm{H}$, Brady LW: Enucleation after plaque radiotherapy for posterior uveal melanoma. Histopathologic findings. Ophthalmology 1990;97: $1665-1670$.
20 Gerdes J, Schwab U, Lemke H, Stein H: Production of a mouse monoclonal antibody reactive with a human nuclear antigen associated with cell proliferation. Int J Cancer 1983; 31:13-20.

21 Onken MD, Worley LA, Ehlers JP, Harbour JW: Gene expression profiling in uveal melanoma reveals two molecular classes and predicts metastatic death. Cancer Res 2004;64: 7205-7209.

22 Gill HS, Char DH: Uveal melanoma prognostication: from lesion size and cell type to molecular class. Can J Ophthalmol 2012;47:246253.

23 Chappell MC, Char DH, Cole TB, Harbour JW, Mishra K, Weinberg VK, Phillips TL: Uveal melanoma: molecular pattern, clinical features, and radiation response. Am J Ophthalmol 2012;154:227-232.e2.

24 Edge SB, Compton CC, Byrd DR (eds): American Joint Committee on Cancer Staging Manual, ed 7. Chicago, Springer, 2010, pp 549-552. 